\title{
O PIERRÔ IRÔNICO DE JULES LAFORGUE
}

\author{
JULES LAFORGUE'S IRONIC PIERROT
}

Nils Goran Skare ${ }^{1}$

\begin{abstract}
RESUMO: Este estudo examina o personagem do pierrô na obra do poeta francês Jules Laforgue, ao analisar um poema alegórico traduzido para o português $\mathrm{O}$ conceito de personagem é retirado da teoria de Jacques Lacan. Primeiro definimos o nó borromeano; depois, o significante-fálico e o significantemestre; após, o ritmo e a voz e, por fim, o personagem. Identificamos, no pierrô laforguiano, um mal na alma e o caracterizamos como irônico. Nossa tese central é que o sentido do personagem é uma origem da narrativa. Definimos origem e narrativa em nossa discussão e concluímos com ideias para estudos futuros.
\end{abstract}

PALAVRAS-CHAVE: Jules Laforgue; Pierrô; personagem; ironia.

ABSTRACT: This study examines the pierrot as a character in the work of French poet Jules Laforgue through the analysis of an allegoric poem. The concept of character is extracted from the theory of Jacques Lacan. In order to do this we first define the Borromean knot; then, the phallic and the master signifiers; then rhythm, voice and character. We identify in the Laforguean pierrot an uneasiness in the soul and we characterize him as ironic. We translate the poem to Portuguese. Our main thesis is that the sense of a character is an origin of the narrative. We define origin and narrative in our discussion and we conclude with ideas for further studies.

KEYWORDS: Jules Laforgue; Pierrot; character; irony.

\section{Introdução}

O poeta francês Jules Laforgue $(1860$ - 1887) é conhecido como um dos primeiros a usar o verso livre na poesia de língua francesa. Embora o público brasileiro não tenha acesso a muito de sua obra - destacamos a excelente antologia Litanias da Lua, de organização e tradução de Régis Bonvicino (1989) -, Laforgue é um nome importante no desenvolvimento da arte poética, tendo sido admirado por autores como T. S. Eliot e Ezra Pound. Este "[...] considerava Laforgue o inventor, ao lado do poeta latino Propércio, da poesia de cunho logopaico, na qual o intelecto dança entre as palavras, prevalecendo ou estabelecendo equilíbrio com as imagens e a música." (BONVICINO, 1989, p. 20).

\footnotetext{
${ }^{1}$ Estudou C. Sociais e Letras na UFPR (Universidade Federal do Paraná), e trabalha atualmente como tradutor e editor; já verteu para o português obras de Mark Twain, Akutagawa Ryunosuke, August Strindberg e E. E. Cummings.
} 
Jules Laforgue nasceu em Montevidéu, mas logo se mudou para Paris, já que a família era de origem francesa. Após fracassar três vezes nos exames para o baccalauréat de filosofia, ele se volta para a literatura. Assim, passa a frequentar um grupo que germinará no simbolismo. Depois do falecimento do pai, muda-se para Berlim onde se torna leitor de francês da imperadora Augusta. Morre com apenas 27 anos ao voltar para Paris, não sem antes deixar uma marca formidável sobre o decadentismo europeu: Laforgue reúne o irônico e o melancólico, poeta do sonho e do cotidiano.

\begin{abstract}
A poesia de Jules Laforgue revela muitos aspectos de insatisfação e mesmo ressentimento que têm relação com o prodigioso desenvolvimento das grandes cidades, com a monotonia da vida provinciana, com a existência rotineira dos empregados e funcionários públicos (fonctionnaires), e com la vie quotidienne em geral, vindo após duas gerações de romantismo nas artes em que o individualismo tinha sido exaltado. (FOWLIE, 1990, p. 11)
\end{abstract}

Nosso propósito, com o presente estudo, é analisar um personagem recorrente nos temas laforguianos: o pierrô. Sabemos que o pierrô é um personagem da comédia italiana que foi transportado para o teatro francês, associado sobretudo à pantomima. Ele aparece em diversos poemas do autor francês, e nossa intenção é delimitar no que consiste esse personagem.

Nosso conceito de personagem é haurido de elementos da teoria de Jacques Lacan (1901 - 1981), nome iniludível no desenvolvimento do pensamento psicanalítico.

Como seria impossível - e inútil - examinar cada um dos poemas em que surge o personagem do pierrô, escolhemos um "tipo ideal", um poema caracterizado pelo próprio autor como representativo da natureza típica do personagem que buscamos compreender.

Ao longo deste artigo, lidamos muitas vezes com o fenômeno da tradução. Apresentamos mesmo uma versão nossa para o poema que abordamos - Pierrots (Scène courte mais typique) (LAFORGUE, 2001, p. 214) - a partir do deslindamento da origem real da obra. Nesse sentido, o presente artigo também se constitui como um projeto de tradução onde, a partir desta primeira exploração da poética laforguiana e da descrição do personagem do pierrô, poderemos estabelecer um modus operandi para outras obras do autor com o mesmo tema.

\title{
1. Conceitos preliminares
}

Para nossa análise, precisaremos do conceito de personagem. Construiremos esse conceito a partir de parte da teoria psicanalítica de Jacques Lacan. Ao realçar o caráter linguístico na constituição do ser humano, Lacan realizou uma revolução copernicana na psicanálise que também tem rendido frutos em outros campos. Nosso itinerário começa pelas três ordens que, para o psicanalista francês, compõem a subjetividade humana: o Imaginário, o Simbólico e o Real. Devemos pensar nesses três registros como inseparáveis; se os descrevemos um por um, é para fins expositivos.

Apresentado na Associação Psicanalítica Internacional em Marienbad, em 1936, e reapresentado em 1949, no Congresso Psicanalítico Internacional em Zurique, o ensaio $O$ estádio do espelho como formador da função do Eu apresenta as primeiras formulações importantes de Lacan com relação ao Imaginário. A criança humana, em contraposição aos filhotes de outros primatas, interessa-se muito por sua imagem no espelho. 
Num primeiro momento, o ego da criança se aliena naquela imagem. Num segundo momento, a criança esquece essa alienação. Perante o espelho, a criança ali se identifica - mas não se reconhece.

A função do estádio do espelho revela-se para nós, por conseguinte, como um caso particular da função da imago, que é estabelecer uma relação do organismo com sua realidade - ou, como se costuma dizer, do Innenwelt [mundo interior] com o Umwelt [mundo circundante]. (LACAN, 1999, p. 100 - grifos e colchetes no original).

O imaginário é o campo do narcisismo, portanto, da violência. No imaginário, identificamos o "outro" com "o" minúsculo; no simbólico reconhecemos o "Outro" com "O" maiúsculo. Ao contrário do Imaginário, o Outro é uma alteridade radical. Mas é essa mesma alteridade absoluta e, sobretudo, essa arbitrariedade que funda o simbólico como domínio da Lei. "Um contrato está por trás da fala e permite que o liame social opere. [...] A Lei é a face social do contrato intersubjetivo da fala. Não é a lei que precisa de legitimidade; a legitimidade é o produto de uma legalidade primeva." (DOUZINAS, 2000, p. 308-309).

O Outro é uma entidade obscura perante a qual o sujeito jamais tem certeza do que é. Enquanto desejamos um objeto, ainda somos animais; assim, para Kojéve,

[...] o desejo que busca um objeto natural só é humano na medida em que é mediatizado pelo desejo de outrem dirigido ao mesmo objeto: é humano desejar o que os outros desejam, porque eles o desejam. Assim, um objeto perfeitamente inútil do ponto de vista biológico [...] pode ser desejado porque é objeto de outros desejos. Tal desejo só pode ser um desejo humano. (KOJÈVE, 2010, p. 13).

O sujeito deseja sempre de maneira tateante e vaga. Ou, na clássica formulação lacaniana: "o desejo do homem é o desejo do Outro" (LACAN, 2001, p. 292).

O terceiro registro é o Real, que está além da linguagem. Como só podemos apreender o mundo mediante a linguagem, o Real é de certa forma inapreensível e se aproxima do em si. Ele é tudo que sobra quando subtraímos a realidade.

Podemos esclarecer o conceito tomando como exemplo o conto de horror "Berenice", de Edgar Allan Poe. O narrador Egeu, dotado do que chama de monomania, tenta descrever os dentes de sua prima e futura esposa:

O bater de uma porta me perturbou e, olhando para cima, vi que minha prima havia deixado o recinto. Mas do encerro confuso do meu cérebro, não tinha, ai de mim! partido e não seria expulso o espectro da alvura e visagem dos dentes. Nem uma mancha em suas superfícies - nem uma sombra no esmalte - nem uma arranhadura nas beiradas - mas o período daquele sorriso havia sido suficiente para marcá-los em minha memória. Eu os via agora melhor do que os vira então. Os dentes! - os dentes! - eles estavam aqui e lá, em todos os lados, à minha frente espalhados; longos, finos, e brancos em excesso, com os pálidos lábios contorcendo-se ao redor, assim qual no exato momento de sua primeira terrível vertigem. (POE, 1990, p. 12 - grifos no original) 
Neste trecho estão presentes algumas características do Real: os dentes escapam à verbalização; a experiência do contato com o Real traumatiza o narrador; os dentes, por fim, são dotados de uma singularidade.

Uma das maneiras indiretas em que notamos o Real é quando há algo insensível à simbolização, é algo que sobra nesse processo. No Real nada falta. Nesse registro, as contradições coexistem.

O Real é a arena da dialética, onde os termos opostos podem coincidir. Distinguindo-se disso, o Imaginário é onde dois termos podem ser reconciliados numa síntese harmônica, e o Simbólico é onde dois termos são definidos diferencialmente, onde um é porque outro não é outra coisa. (MYERS, 2003, p. 27-28 - grifos no original)

O trauma, a psicose e a morte estão do lado do Real.

Esses são os três registros da subjetividade humana para Lacan, conhecidas como nó borromeano. Podemos agora entrar na parte de interesse mais nitidamente semiótico de sua teoria.

Para Saussure (2003), a unidade mínima do universo linguístico é o signo, composto pelo significante e pelo significado, como dois lados de uma folha de papel. Lacan subverte esse conceito ao estabelecer o significante como unidade mínima, como se a folha de papel virasse agora uma fita de Möbius. ${ }^{2}$ Os significantes passam a ser como fábricas que geram significado e podem ser compreendidos em eixos paradigmáticos/metafóricos ou sintagmáticos/metonímicos.

Há dois significantes especiais a serem observados: o significante-fálico e o significante-mestre. O primeiro é aquele que se destaca numa cadeia de significantes; o segundo, aquele que a completa.

Quanto ao significante-fálico, operando nos três registros, é um significante que indica a diferença sexual. A criança se encontra inicialmente num estado de unidade com a mãe, contudo essa unidade se desfaz porque a mãe deseja, e desejar é faltar. Temos uma tríade mãe, criança e objeto desejado. Quando a criança percebe essa falta na mãe, a criança forma uma noção sobre o objeto que acredita que a mãe deseja. Esse objeto é o significantefálico.

O significante-fálico (expresso por Lacan pela letra $\varphi$ ) é aquilo que releva a diferença entre os significantes.

Enquanto o inconsciente localiza o poder na Alteridade, o significante-fálico, por contraste, localiza o poder na subjetividade. Ao contrário da unidade do imago imaginário, que provê um marcador referencial simples, o significante fálico simbólico constrange o Outro ao abotoar uma significação, uma identificação e um discurso num só único pacote arrumado. (PELT, 2000, p. 153).

Por outro lado, o significante-mestre (representado pela expressão S(A) por Lacan) é aquilo que completa uma cadeia significante. Ele é um pequeno pedaço do Real que é nonsense e, nessa medida, ele é a identificação do sujeito com essa porção real que lhe assegura uma certa estabilidade entre os absurdos e o caos da vida. Não importa quantos

\footnotetext{
${ }^{2}$ A fita de Möbius é uma estrutura topológica criada a partir de uma folha de papel onde se prendem as pontos, formando uma fita, após ser feita uma torção no papel. Se traçamos uma linha com uma caneta, percebemos que é uma superfície contínua, isto é, trata-se de uma folha de papel com um lado só. (JAMES; JAMES, 1992).
} 
significantes sejam reunidos numa cadeia significante, é a falta, materializada no significantemestre, que a completa. Para fazermos uma comparação, o significante-mestre é como uma moeda estrangeira, uma coisa sem um valor econômico propriamente dito, em si mesmo inútil, mas que lembra a seu dono de um modo peculiar uma viagem feita a um país no exterior - ele tampa a ordem simbólica dos significantes referentes àquela viagem.

De posse desses dois significantes, podemos elaborar uma estrutura operacional do que chamaremos de ritmo.

Ritmo é um termo elusivo, mesmo para músicos experientes, que facilmente o declarariam absolutamente subjetivo e irredutível a qualquer conceitualização. $\mathrm{Na}$ verdade, nos termos aqui delineados, o ritmo existe como fluxo pulsional caótico. Remetemos à distinção feita pela psicanalista e romancista francesa Julia Kristeva (nascida em 1941) entre o semiótico (irracional, corporal, inconsciente, musical) e o simbólico (racional, mental, consciente, linguístico).

Cargas 'energéticas' ao mesmo tempo que marcas 'psíquicas', as pulsões articulam assim o que nós chamamos de uma chora: uma totalidade não expressiva constituída por essas pulsões e suas êxtases, numa mobilidade tão movimentada (...) [que] a própria chora - na medida que é ruptura e articulações - ritmo - é anterior à prova, ao verossímil, à espacialidade e à temporalidade. (KRISTEVA, 1974, p. 23 - grifos nossos).

O ritmo faz os significantes se articularem fluidamente, existindo previamente a interpretações. Como no semiótico kristevaniano, há uma irracionalidade que faz do ritmo um movimento aberto e caótico:

Um labirinto imaginário, uma composição simbólica, um brilho real: o ritmo está ligado ao significante-fálico e ao significante-mestre, seja pela diferença, seja pela repetição. Repetindo e diferindo/deferindo, o ritmo joga com os significantes de uma ordem simbólica dentro da clausura que a 'emoldura'. (SKARE, 2009, p. 51).

estrutura.

É possível descrever o ritmo através de um esquema que descreve essa

Tabela 1 - Representação esquemática da estrutura do ritmo

\begin{tabular}{|l|l|l|}
\hline & Significante-fálico $\varphi$ & Significante-mestre S(A) \\
\hline Repetição & R $\varphi($ Quadrante 1$)$ & R S(A) (Quadrante 3) \\
\hline Diferença & D $\varphi($ Quadrante 2$)$ & D S(A) (Quadrante 4) \\
\hline
\end{tabular}

Na diferença, "o novo"; na repetição, o "de novo". É o ritmo de uma dada ordem sócio-simbólica que impulsiona sua interpretação. A possibilidade aqui descrita de formalizar esse ritmo é um passo na abstração e na objetivação do caos da chora. Aquilo que entendemos como desprovido de ritmo acaba se tornando insignificante.

Do mundo pulsional caótico do ritmo, emerge a voz (que representamos pela letra $\omega$ ). A subjetividade, em contato com o rítmico, busca um sentido, e isso que ela encontra é o que se chama de voz. A partir daí pode nascer a interpretação (SKARE, 2011). A voz é um elo que passa da estrutura formalizada do ritmo para um elemento mais complexo: a estrutura do personagem. O personagem é uma estrutura que se encontra num nível superior 
ao do ritmo; o nível é uma noção essencial na natureza articulada da linguagem e que permite encontrar, na complexidade formal, a arquitetura entre o todo e as partes (LEFÈBVRE, 1969).

Como articulação de voz e ação, o personagem é um conceito interpretável, delineado e formalizável. É pela voz do ritmo que se chega à formalização do personagem. Em termos esquemáticos, é possível representar o personagem desta forma:

Tabela 2 - Representação esquemática da estrutura do personagem

\begin{tabular}{|l|l|l|}
\hline & Ação $(\alpha)$ & Voz $(\omega)$ \\
\hline Repetição & Repetição da Ação (Quadrante 1) & Repetição da Voz (Quadrante 3) \\
\hline Diferença & Diferença da Ação (Quadrante 2) & Diferença da Voz (Quadrante 4) \\
\hline
\end{tabular}

\section{A análise do objeto}

O pierrô é um dos personagens constantes na obra poética de Jules Laforgue. Para traçar suas características, é preciso imergir nas minúcias do próprio texto. Assim, buscaremos dentro do corpus poético do autor um momento privilegiado, uma instância textual a partir da qual traçar a natureza desse personagem. Abordamos, assim, inicialmente um poema de forte conotação alegórica e uma espécie de síntese do pierrô na obra laforguiana para depois procurarmos uma abstração do que encontramos.

\section{1 "Pierrots (Scène courte mais typique)"}

No livro L'Imitation de Notre-Dame la Lune - segundo livro de poemas de Laforgue e onde encontraremos de forma mais recorrente a figura do pierrô - há um poema intitulado "Pierrots (Scène courte mais typique)" (LAFORGUE, 2001, p. 214), ou "Pierrôs (cena curta mas típica)". Esse poema é especialmente interessante pelo fato de ser uma cena típica, isto é, primeiramente, uma construção explicitamente dramática (donde a nossa importância para a construção da personagem), inclusive com a indicação Exit ao fim do poema; e, em segundo lugar, também pelo fato de ser declarada pelo próprio autor como uma obra característica.

O poema contém 9 estrofes; cada uma, com três versos (exceto a última estrofe que apresenta o terceto "quebrado"); cada verso dentro de sua estrofe rima um com o outro. Os versos são, no geral, alexandrinos, mas alguns são decassílabos ou hendecassílabos. Comentamos as estrofes uma a uma, oferecendo uma possível tradução ${ }^{3}$ sem, por enquanto, preocupações de ordem estética.

\footnotetext{
${ }^{3}$ Não falamos em "tradução livre" na medida em que a contraposição "fiel" versus "livre" corresponde a um paradigma que entende como possível/desejável uma equivalência linguística, o que não pode ser sustentado dentro dos moldes deste artigo. Diremos apenas que é uma tradução feita sem a preocupação com a totalidade do poema, ou antes, uma tradução "de consulta" mais do que "estética". Posteriormente apresentamos uma tradução tal qual entendemos o processo.
} 
Tabela 3 - Primeiro terceto de "Pierrots (Scène courte mais typique)"

\begin{tabular}{|l|l|l|l|l|l|}
\hline $\mathbf{N}^{\mathbf{}}$. & \multicolumn{1}{|c|}{ VERSO } & METR. & TRANSC. & RIMA & BORROM. \\
\hline 1 & $\begin{array}{l}\text { "Il me faut vos yeux! Dès que je perds leur } \\
\text { étoile," }\end{array}$ & 12 & /e.twal/ & \multirow{2}{*}{ /wal/ } & Imaginário \\
\cline { 1 - 4 } 2 & $\begin{array}{l}\text { "Le mal des calmes plats s'engouffre dans } \\
\text { ma voile," }\end{array}$ & 10 & /vwal/ & & Real \\
\cline { 1 - 4 } 3 & $\begin{array}{l}\text { "Le frisson du Vae soli! gargouille en mes } \\
\text { moelles..." }\end{array}$ & 12 & /mwal/ & & Simbólico \\
\hline
\end{tabular}

Nesse terceto, cuja rima é /wal/, encontramos um verso pertencente a cada um dos registros borromeanos.

"Preciso dos teus olhos! Desde que perdi a estrela deles". O primeiro verso é claramente imaginário, na medida em que relata uma visão necessária, isto é, que fala da necessidade de ser visto ou de ter olhos de outrem para conseguir enxergar.

"O enjoo das calmarias engolfa meu barco a vela". O segundo verso, por sua vez, é real, pois trata de um paradoxo, de uma contradição: como pode uma calmaria conduzir um barco a vela para o alto mar?

"O calafrio do Vae soli! gorgoleja na minha medula" - O Vae soli! que este verso menciona significa "ai do solitário!" e vem de Eclesiastes 4:10: "Além do que, se um cai, o outro o levanta. Mas ai daquele que está só! Se cai, não há outro a levantá-lo." O centro desse verso é uma expressão, um dito, um enunciado; de tal forma, pertence claramente ao simbólico.

Tabela 4 - Segundo terceto de "Pierrots (Scène courte mais typique)"

\begin{tabular}{|c|c|c|c|c|c|}
\hline $\mathbf{N}^{0}$. & VERSO & METR & TRANSC & RIMA & BORROM \\
\hline 4 & "Vous auriez dî me voir après cette querelle!" & 12 & /kə.B\&l/ & \multirow{3}{*}{$/ \varepsilon 1 /$} & Imaginário \\
\hline 5 & "J'errais dans l'agitation la plus cruelle," & 10 & /kьу.єl/ & & Simbólico \\
\hline 6 & $\begin{array}{l}\text { "Criant aux murs: Mon Dieu! mon Dieux! Que } \\
\text { dira-t-elle?" }\end{array}$ & 12 & $/ \varepsilon 1 /$ & & Simbólico \\
\hline
\end{tabular}

Nesse terceto, não encontramos nenhum verso pertencente à ordem do Real.

"Vós deveríeis ter me visto após essa querela!". O verso quarto fala novamente da necessidade de ser visto, referindo-se a uma imagem, bem como a uma certa violência.

"Eu vagava na agitação mais cruel". Este quinto verso trata de uma perturbação pela qual o pierrô "vaga": estar perdido, estar enrodilhado, é coisa do simbólico.

“Gritando aos muros: Meu Deus! meu Deus! O que ela dirá?". O último verso desse terceto, além de uma explícita referência à linguagem, também trata de um "pensar o que Outro está pensando", é simbólico, portanto.

Tabela 5 - Terceiro terceto de "Pierrots (Scène courte mais typique)"

\begin{tabular}{|c|c|c|c|c|c|}
\hline $\mathbf{N}^{\circ}$. & $\begin{array}{l}\text { VERSO } \\
\end{array}$ & METR. & TRANSC. & RIMA & BORROM. \\
\hline 7 & $\begin{array}{l}\text { "Mais aussi, vrai, vous me blessâtes } \\
\text { aux antennes" }\end{array}$ & 12 & /ã.ten/ & \multirow[t]{3}{*}{$/ \varepsilon n /$} & Imaginário \\
\hline 8 & $\begin{array}{l}\text { "De l'âme, avec les mensonges de votre } \\
\text { traîne," }\end{array}$ & 12 & $/ \mathrm{t} \operatorname{s} \varepsilon \mathrm{n} /$ & & Simbólico \\
\hline 9 & $\begin{array}{l}\text { "Et votre tas de complications } \\
\text { mondaines." }\end{array}$ & 11 & $/ \mathrm{m} \tilde{\partial} . \mathrm{d} \varepsilon \mathrm{n} /$ & & Simbólico \\
\hline
\end{tabular}


Nesse terceto tampouco encontramos um verso do real.

"Mas também, verdade, você me fere as antenas". Imaginário, na medida em que envolve uma violência e também uma percepção imaginária do próprio pierrô como dotado de um órgão corporal diferente.

"Da alma, com as mentiras a reboque": só se pode mentir no simbólico.

"E seus montes de complicações mundanas". As complicações mundanas envolvem, novamente, um enrodilhamento nos significantes do Simbólico.

Tabela 6 - Quarto terceto de "Pierrots (Scène courte mais typique)"

\begin{tabular}{|c|c|c|c|c|c|}
\hline $\mathbf{N}^{\mathbf{o}}$. & VERSO & METR. & TRANSC. & RIMA & BORROM. \\
\hline 10 & $\begin{array}{l}\text { "Je voyais que vos yeux me lançaient sur } \\
\text { des pistes," }\end{array}$ & 12 & /pist/ & \multirow[t]{3}{*}{ /ist/ } & Imaginário \\
\hline 11 & $\begin{array}{l}\text { "Je songeais: oui, divins, ces yeux! mais } \\
\text { rien n'existe" }\end{array}$ & 12 & /Eg.zis.t/ & & Real \\
\hline 12 & "Derrière! Son âme est affaire d'oculiste." & 10 & /o.ky.list/ & & Simbólico \\
\hline
\end{tabular}

Nesse terceto encontramos também um verso pertencente a cada um dos registros borromeanos.

"Eu via que vossos olhos me lançavam em pistas": esse décimo verso é claramente imaginário, pois temos novamente a visualidade como guia para o logro e as possíveis "pistas" que permitem contorná-lo.

"Eu sonhava: sim, divinos, esses olhos! mas nada existe": aqui temos contato com o sonho e um "nada" que "não existe", remetendo-nos ao real.

"Atrás! A alma dela é coisa de oculista.": essa formulação irônica pertence ao simbólico; o significante "alma" é reconhecido como ilusório, o logro é desfeito.

Tabela 7 - Quinto terceto de "Pierrots (Scène courte mais typique)"

\begin{tabular}{|c|c|c|c|c|c|}
\hline $\mathbf{N}^{\mathbf{0}}$. & VERSO & METR. & TRANSC. & RIMA & BORROM. \\
\hline 13 & "Moi, je suis laminé d'esthétiques loyales!" & 12 & /lwa.jal/ & \multirow{3}{*}{ /al/ } & Simbólico \\
\hline 14 & $\begin{array}{l}\text { "Je hais les trémolos, les phrases } \\
\text { nationales;" }\end{array}$ & 12 & /na.sjo.nal/ & & Simbólico \\
\hline 15 & $\begin{array}{l}\text { "Bref, le violet gros deuil est ma couleur } \\
\text { locale." }\end{array}$ & 12 & /lo.kal/ & & Simbólico \\
\hline
\end{tabular}

"Eu, eu sou laminado em estéticas leais / Odeio os trêmolos, as frases nacionais / Em suma, o roxo do grande luto é minha cor local.". Esse terceto inteiro remete a uma espacialidade e a uma coloração (tanto no sentido da cor visual quanto da cor regional), constituindo-se assim um elemento simbólico.

Tabela 8 - Sexto terceto de "Pierrots (Scène courte mais typique)"

\begin{tabular}{|c|c|c|c|c|c|}
\hline $\mathbf{N}^{\mathbf{0}}$. & VERSO & METR. & TRANSC. & RIMA & BORROM. \\
\hline 16 & $\begin{array}{l}\text { “Je ne suis point 'ce gaillard-là!' ni Le } \\
\text { Superbe!” }\end{array}$ & 12 & /sy.pesb/ & \multirow{3}{*}{ /єьb/ } & Simbólico \\
\hline 17 & $\begin{array}{l}\text { "Mais mon âme, qu'un cri un peu cru } \\
\text { exacerbe," }\end{array}$ & 12 & /\&g.za.s\&ьb/ & & Simbólico \\
\hline 18 & "Est au fond distinguée et franche comme & 11 & /\&ьb/ & & Simbólico \\
\hline
\end{tabular}


'Não sou de forma alguma 'esse gaiato aí!' nem O Soberbo / Mas minha alma, que um grito um pouco cru exacerba / É no fundo distinta e franca como uma erva”. Esse terceto novamente é todo simbólico: em primeiro lugar, no verso 16 , pela menção à própria expressão linguística enquanto expressão (o uso das aspas); mas também porque a "alma" agora retorna, como alma do próprio pierrô, sensível a gritos e comparada à erva.

Tabela 9 - Sétimo terceto de "Pierrots (Scène courte mais typique)"

\begin{tabular}{|c|c|c|c|c|c|}
\hline $\mathbf{N}^{0}$. & VERSO & METR. & TRANSC. & RIMA & BORROM. \\
\hline 19 & $\begin{array}{l}\text { "J'ai des nerfs encor sensibles au son des } \\
\text { cloches," }\end{array}$ & 12 & $/ \mathrm{kl} \supset \int /$ & \multirow[t]{3}{*}{ Io $\int /$} & Simbólico \\
\hline 20 & $\begin{array}{l}\text { "Et je vais en plein air sans peur et sans } \\
\text { reproch," }\end{array}$ & 12 & /ьә.рьэЛ/ & & Simbólico \\
\hline 21 & $\begin{array}{l}\text { "Sans jamais me sourire en un miroir de } \\
\text { poche." }\end{array}$ & 12 & $/ \mathrm{p} \supset \int /$ & & Imaginário \\
\hline
\end{tabular}

"Tenho os nervos ainda sensíveis ao som dos relógios, / e vou em pleno ar sem medo nem reprimenda". Os versos 19 e 20 mencionam o sentimento e sua percepção no corpo ("nervos"), inscrevendo-os no campo do simbólico.

"Sem jamais me sorrir num espelho de bolso.": nitidamente imaginário por sua referência à imagem especular.

Tabela 10 - Oitavo terceto de "Pierrots (Scène courte mais typique)"

\begin{tabular}{|l|l|l|l|l|l|}
\hline $\mathbf{N}^{\mathbf{0}}$. & \multicolumn{1}{|c|}{ VERSO } & METR. & TRANSC. & RIMA & BORROM. \\
\hline 22 & $\begin{array}{l}\text { "C'est vrai, j'ai bien roulé! J'ai râlé dans } \\
\text { des gîtes" }\end{array}$ & 12 & /3it/ & \multirow{2}{*}{ /it/ } & Simbólico \\
\cline { 1 - 4 } 23 & $\begin{array}{l}\text { "Peu vous; mais, n'en ai-je pas plus de } \\
\text { mérite" }\end{array}$ & 11 & /me.sit// & & Simbólico \\
\cline { 1 - 4 } 24 & $\begin{array}{l}\text { "A en avoir sauvé la foi en vos yeux? } \\
\text { Dites..." }\end{array}$ & 12 & /dit/ & & Simbólico \\
\hline
\end{tabular}

"É verdade, eu me mudei bastante! Me mudei pelos alojamentos / Não em você; mas, não tenho acaso o mérito; de ter mantido a fé em vossos olhos? Diga...". Todo esse terceto é simbólico, pois, além de outros motivos, menciona ideais (significantes do simbólico) como "verdade", "mérito" e "fé".

Tabela 11 - Estrofe final de "Pierrots (Scène courte mais typique)"

\begin{tabular}{|c|c|c|c|c|c|}
\hline $\mathbf{N}^{\circ}$. & $\begin{array}{c}\text { VERSO } \\
\end{array}$ & METR. & TRANSC. & RIMA & BORROM. \\
\hline 25 & $\begin{array}{l}\text { "Allons, faisons la paix, Venez, que je vous } \\
\text { berce," }\end{array}$ & 12 & /bebs/ & \multirow{4}{*}{ /\&ьs/ } & \multirow{2}{*}{ Simbólico } \\
\hline $26 \mathrm{a}$ & "Enfant. Eh bien?" & 4 & - & & \\
\hline $26 b$ & pardon me verse" & 8 & /vebs/ & & \multirow[t]{2}{*}{ Imaginário } \\
\hline 27 & $\begin{array}{l}\text { "Un mélange (confus) d'impressions... } \\
\text { Diverses..." }\end{array}$ & 11 & /di.vebs/ & & \\
\hline
\end{tabular}


"Vamos, façamos as pazes. Venha que eu te ninarei / Criança. Está bem?". Os versos 25 e 26a, que compõem a mesma elocução, referem-se a um pedido de perdão e conciliação (simbólicos, registro da Lei).

"É que o teu perdão me versa / um amontoado (confuso) de impressões... diversas...". Os últimos versos, 26 b e 27 , pertencem ao imaginário, pois mostram como esse perdão desperta uma "confusão" difusa, um "impressionismo" de coisas múltiplas.

Após essa primeira aproximação, examinaremos agora, mais detalhadamente, os versos que atribuímos ao real, já que localizar o significante-mestre é crucial para nossa investigação.

“Le mal des calmes plats s'engouffre dans ma voile," (verso 2)

$\mathrm{O}$ enjôo das calmarias engolfa meu barco a vela

"Je songeais: oui, divins, ces yeux! mais rien n'existe" (verso 11)

Eu sonhava: sim, divinos, esses olhos! mas nada existe

O real é o reino do não sentido. O simbólico cava seu espaço significante a partir do real. A partir de 1963, o a (objet-petit a) passa a adquirir conotações do real. Segundo Jacques-Alain Miller:

"É precisamente porque o objeto $a$ é removido do campo da realidade que ele o emoldura. [...] O objeto $a$ [...] é um tal fragmento, e é sua subtração da realidade que a emoldura. $\mathrm{O}$ sujeito, como sujeito barrado - como ser-emfalta - é esse buraco. Como ser, não é nada além do pedaço subtraído. De onde a equivalência entre o sujeito e o objeto $a$." (MILLER apud ŽIŽEK, 1992, p. 94).

Em outras palavras: estamos procurando o $a$ a partir do qual se escava, do qual se emoldura todo o poema. Vamos representar os dois versos conjuntamente, sob sua transcrição fonética, dividindo as sílabas com "parêntesis" e marcando em negrito as sílabas tônicas.

(lə) (mal) (de) (kalm) (pla) (sã) (gu) (fbe) (dã) (ma) (vwal)

E o outro verso:

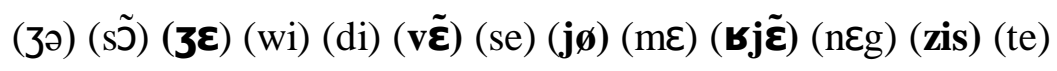
conjunto só:

Esta é a tabela de frequências dos fonemas dos dois versos entendidos num

Tabela 12 - Tabela de frequência dos fonemas nos versos ligados ao Real

\begin{tabular}{|l|l|}
\hline Fonema & Frequência \\
\hline & \\
\hline$/ \mathrm{l} /$ & 5 \\
\hline$/ \mathrm{m} /$ & 4 \\
\hline$/ \mathrm{a} /$ & 4 \\
\hline
\end{tabular}

Disponível em: http://seer.fclar.unesp.br/casa 
CASA, Vol.10 n.1, julho de 2012

\begin{tabular}{|l|l|}
\hline$/ \mathrm{s} /$ & 4 \\
\hline$/ \mathrm{d} /$ & 3 \\
\hline$/ \mathrm{e} /$ & 3 \\
\hline$/ \mathrm{z} /$ & 3 \\
\hline$/ \mathrm{\varepsilon} /$ & 3 \\
\hline$/ \mathrm{i} /$ & 3 \\
\hline$/ \mathrm{a} /$ & 2 \\
\hline$/ \tilde{\mathrm{a}} /$ & 2 \\
\hline$/ \mathrm{g} /$ & 2 \\
\hline$/ \mathrm{b} /$ & 2 \\
\hline$/ \mathrm{v} /$ & 2 \\
\hline$/ \mathrm{w} /$ & 2 \\
\hline$/ \tilde{\varepsilon} /$ & 2 \\
\hline$/ \mathrm{k} /$ & 1 \\
\hline$/ \mathrm{p} /$ & 1 \\
\hline$/ \mathrm{u} /$ & 1 \\
\hline$/ \mathrm{f} /$ & 1 \\
\hline$/ \tilde{\mathrm{o}} /$ & 1 \\
\hline$/ \mathrm{j} /$ & 1 \\
\hline$/ \varnothing \varnothing /$ & 1 \\
\hline$/ \mathrm{n} /$ & 1 \\
\hline$/ \mathrm{z} /$ & 1 \\
\hline$/ \mathrm{t} /$ & 1 \\
\hline
\end{tabular}

Notamos que o fonema /// é o mais produtivo. Esse é o nosso significantemestre: /1/. Notamos também que as 5 ocorrências de /1/ se concentram no verso (2), ao passo que no verso (11) não há nenhum ocorrência.

"Le mal des calmes plats s'engouffre dans ma voile,"

(lə) (mal) (de) (kalm) (pla) (sã) (gu) (fbe) (dãa) (ma) (vwal)

Notamos também que, em 3 das 5 sílabas em que /1/ aparece, está presente o som /al/. Aqui está como traduzimos esse verso (2), encontrando aqui um "mal" na "alma" do pierrô.

o MAL da cALMA engolfa-me a vela,

Notamos um jogo entre as letras [a], [1] e [m]; dentro de "calma" está "alma"; e dentro da "alma" está o "mal". A partir disso, desse jogo de letras, irrompe uma origem poética, que permite, depois, reconstruir o poema em português, agora uma tradução apropriada, tal qual se segue:

\section{PIERRÔS}

(cena curta mais típica) 
Quero teus olhos! Deles perdi a estrela,

E o mal da calma engolfa-me a vela,

O frisson do Vae soli! gargoleja em minha goela...

Deverias me ver após essa querela!

Vaguei em agitação cruel a

Gritar aos muros: Deus! Que dirá ela?

Mas também, me feriste nas antenas

Da alma, com as mentiras com que enganas

E tua porção de complicações mundanas.

Eu via teus olhos me levar a uma pista,

Eu sonhava: sim, divinos olhos! mas nada existe

Por trás! Sua alma é coisa para oculista.

$\mathrm{Eu}$, sou laminado em estéticas leais!

Odeio os trêmolos, os bordões nacionais;

Enfim, roxo e luto são minhas cores locais.

Não sou nem "este galhardo" nem O Soberbo!

Minha alma, um grito grave me exacerba,

No fundo é distinta e franca como a erva.

Tenho os nervos sensíveis ao sino que ouço,

E vou em pleno ar, não temo nem me acuso,

Sem jamais me sorrir num espelho de bolso.

Andei por aí! Por mais de um bodeguito,

Pouco por ti; mas não tenho mais mérito

A ter mantido a fé em teus olhos? Teu dito...

"Vamos fazer as pazes, te ponho no berço,

Minha criança. E então?"

"No teu perdão me verso

Em (confusa) mistura de um sinal... Diverso..."

(Exit)

\subsection{O personagem do pierrô}

Encontramos um mal na alma do pierrô. A "alma" é o significante-mestre desse pierrô, e o "mal" seu significante-fálico. A alma é o que completa o pierrô, personagem tipicamente ingênuo e sentimental. O mal é isso que "salta" em sua análise, que conduz tanto ao estranhamento quanto à sua caracterização laforguiana.

Traçamos a matriz do ritmo de acordo com esses dois elementos.

Tabela 13 - Representação esquemática do ritmo do pierrô

\begin{tabular}{|l|l|l|}
\hline & $\varphi(\mathrm{mal})$ & $\mathrm{S}(\mathrm{A})$ (alma) \\
\hline Repetição & Perversão & Espiritualidade \\
\hline
\end{tabular}




\begin{tabular}{|l|l|l|}
\hline Diferença & Saber & Imortalidade \\
\hline
\end{tabular}

Consideramos cada um desses quadrantes:

No Quadrante 1, interpretamos $\mathrm{R} \varphi$ como a perversão. O termo indica a crueldade e a injustiça na ação, isto é, uma malevolência feita com a intenção de infligir ainda mais dor à vítima.

No Quadrante 2, interpretamos D $\varphi$ como o saber. No contexto judaico-cristão dentro do qual Jules Laforgue existe, a Queda do Homem se dá com o ato de comer o "Fruto da Árvore do Conhecimento do Bem e do Mal", tal qual descrito na Gênese bíblica. Não são poucos os escoliastas que identificavam o bem à ação e o mal ao saber (BENJAMIN, 2004).

No Quadrante 3, interpretamos R S(A) como a espiritualidade. Compreender tudo "em termos de alma" significa a busca da importância maior, do transcendente e do metafísico.

No Quadrante 4, interpretamos D S(A) como a imortalidade. Novamente, no contexto judaico-cristão em que existe esse poema, a alma é uma parte do homem distintamente imortal, destinado a felicidades ou danações eternas.

A partir disso, diremos que a voz que emerge a partir desse ritmo é travessa. A travessura é, justamente, uma maldade de criança, onde há habilidade para fazer rir e, ao mesmo tempo, uma certa malícia. Travessa dizemos da voz que vimos emergir a partir de nossa interpretação dessa estrutura rítmica na medida em que, como se diz a respeito de uma criança, ela não sabe exatamente o mal que está fazendo; não é nenhum perversão, coisa que não lhe compromete a imortalidade da alma ao mesmo tempo que contém ainda uma certa espiritualidade, um quê espirituoso. Se o pierrô tem algum mal na alma, personagem ingênuo que é, é para cometer travessuras.

Mas, ao mesmo tempo, precisamos descobrir a ação do pierrô. E é esta: ser perdoado. Nesse poema, podemos depreender essa ação a partir do diálogo final. O pierrô faz as pazes com seu interlocutor.

Tabela 14 - Representação esquemática do personagem do pierrô

\begin{tabular}{|l|l|l|}
\hline & $(\alpha)$ (Fazer as Pazes) & $(\omega)$ (Travessura) \\
\hline Repetição & Sereno & Insuportável \\
\hline Diferença & Rendição & Intelecto \\
\hline
\end{tabular}

No Quadrante 1, interpretamos $\mathrm{R} \alpha$ como o sereno. Fazer as pazes repetidas vezes se torna o fazer a paz, livre de preocupações ou sentimentos de animosidade.

No Quadrante 2, interpretamos D $\alpha$ como a rendição. A partir do momento em que uma das partes de uma disputa se rende, é feita a paz.

No Quadrante 3, interpretamos R $\omega$ como o insuportável. A travessura tem o propósito de provocar, e aquela travessura que é feita repetidas vezes acaba por se tornar insuportável (do contrário, desiste-se dele, e ela não é mais repetida).

No Quadrante 4, interpretamos D $\omega$ como o intelecto. Só pode se exprimir uma travessura se houver isso a que chamamos de intelecto, isto é, uma capacidade de conferir um sentido (espirituoso) a uma troça.

ironia.

Diremos que o determinante da matriz desse personagem, seu sentido, é a

Podemos agora formular a tese deste artigo: o sentido de um personagem dá origem a uma narrativa. 


\section{DISCUSSÃO}

Para discutirmos o que entendemos pela afirmação de que o sentido de um personagem dá origem a uma narrativa, elaboraremos a respeito do conceito de narrativa e de origem.

Narrar é agir. Narrar suspende o Simbólico. A modernidade esvazia a comunicação de experiência, como já sabemos desde Walter Benjamin (1996). Informamos e somos informados cada vez mais, porém isso não tornou nossa vida mais rica. É que a informação já explica tudo e já fornece o comentário que devemos fazer perante a onipresente pergunta "você viu?".

Dessa forma, o desaparecimento do ato de narrar na modernidade significa uma incomunicabilidade, um processo que não chega a alcançar a memória, o memorável, aquilo que merece ser salvo do esquecimento e das ações deletérias do tempo. Uma quantidade de informações muito grande - e que pode chegar a seu "consumidor" cada vez mais rápido e segmentadamente do que era possível até bem pouco tempo - satura a consciência do sujeito, sem que este tire daí algo a ser recordado. (SKARE, 2010a, p. 10).

O narrador é - ou pelo menos era - o transmissor da sabedoria e do conhecimento haurido da própria vida. O narrador sabe dar conselhos. Em grande medida, a narrativa está ligada a um outro tempo, que é o tempo de trabalho artesanal. A narrativa é estranha ao trabalho industrial alienado.

Quanto mais o ouvinte se esquece de si mesmo, mais profundamente se grava nele o que é ouvido. Quando o ritmo do trabalho se apodera dele, ele escuta as histórias de tal maneira que adquire espontaneamente o dom de narrá-las. Assim se teceu a rede em que está guardado o dom narrativo. E assim essa rede se desfaz hoje por todos os lados, depois de ter sido tecida, há milênios, em torno das mais antigas formas de trabalho manual. (BENJAMIN, 1996, p. 205).

A ordem simbólica do narrador tem um embasamento real, na medida em que a própria solidez do trabalho artesanal porta as marcas da existência como experiência. Em certo sentido, o imaginário do narrador é eterno. Seu oposto é o indivíduo superinformado que pode comentar qualquer coisa, desde que ela não dure mais do que um instante.

Definiremos portanto a narrativa como uma predicação simbólica do Real.

Há um ponto importante a ser abordado aqui que diz respeito à passagem do gênero lírico para o narrativo. Quando lemos um poema claramente lírico, é lícito falar numa "narrativa" que se dá dentro desse poema? Laurent Jenny (apud THOMPSON, 1997, p.12) vê, na ordem metafórica do texto poético, um texto segundo onde há um desenrolar:

Será que os poemas, por mais líricos que sejam, não nos contam também algumas "histórias"? Esse sentimento por vezes, numa leitura, de que é "toda uma vida' que eles narram em silêncio, selado no metal de poucas palavras... O que faz a originalidade da temporalidade poética, é que ela é exclusivamente ligada à enunciação, sem o jogo com um tempo referencial, fora do texto (...) 
Quando falamos numa predicação simbólica do Real, tratamos de um desenrolar no tempo, já que o Simbólico existe temporalmente; essa simbolização pode dizer respeito inclusive a uma "temporalidade poética", nos dizeres de Laurent Jenny.

Quanto ao conceito de origem, precisamos, antes de mais nada, esclarecer que não o entendemos como uma espécie de começo, princípio ou gênese. Tomamos origem (Ursprung) no sentido atribuído ao termo novamente por Walter Benjamin.

\begin{abstract}
'Origem' não designa o processo de devir de algo que nasceu, mas antes aquilo que emerge do processo de devir e desaparecer. A origem insere-se no fluxo do devir como um redemoinho que arrasta no seu movimento o material produzido no processo de gênese. O que é próprio da origem nunca se dá a ver no plano do factual, cru e manifesto. O seu ritmo só se revela a um ponto de vista duplo, que o reconhece, por um lado como restauração e reconstituição, e por outro como algo de incompleto e inacabado. Em todo o fenómeno originário tem lugar a determinação da figura através da qual uma ideia permanentemente se confronta com o mundo histórico, até atingir a completude na totalidade da sua história. A origem, portanto, não se destaca dos dados factuais, mas tem a ver com sua pré- e pós-história. Na dialética inerente à origem, encontra a observação filosófica o registo das suas linhasmestras. (BENJAMIN, 2004, p. 32).
\end{abstract}

Diremos que a origem é o encontro dos extremos na Ideia.

Feita essa preparação, o que entendemos quando dizemos que o sentido do personagem pode ser a origem de uma narrativa?

O sentido é a determinante da matriz do personagem. O sentido de um nível diz respeito à sua articulação num nível superior (assim como o sentido dos fonemas os articula em palavras e o sentido das palavras as articula em frases). Esse plano superior que buscamos é justamente o plano da narrativa, e o ponto do sentido do personagem pode determinar a narrativa. A narrativa se dá no espectro de seu personagem. Seus extremos delimitam-lhe a Ideia. Podemos representar a situação atual da seguinte figura.

Podemos nos perguntar agora pela narrativa em que está presente o pierrô de Jules Laforgue. Pode-se afirmar que será uma narrativa de origem irônica. Se a ironia é o uso da linguagem num sentido diverso ou mesmo oposto do que se quer dar a entender, então a narrativa do pierrô laforguiano possuirá sempre uma outra interpretação. É claro que qualquer texto pode receber uma leitura tal que revele um sentido distinto do literal; contudo defendemos que, em Laforgue, esse procedimento faz parte do jogo, parte da própria fruição do poema e está inscrito nele. 


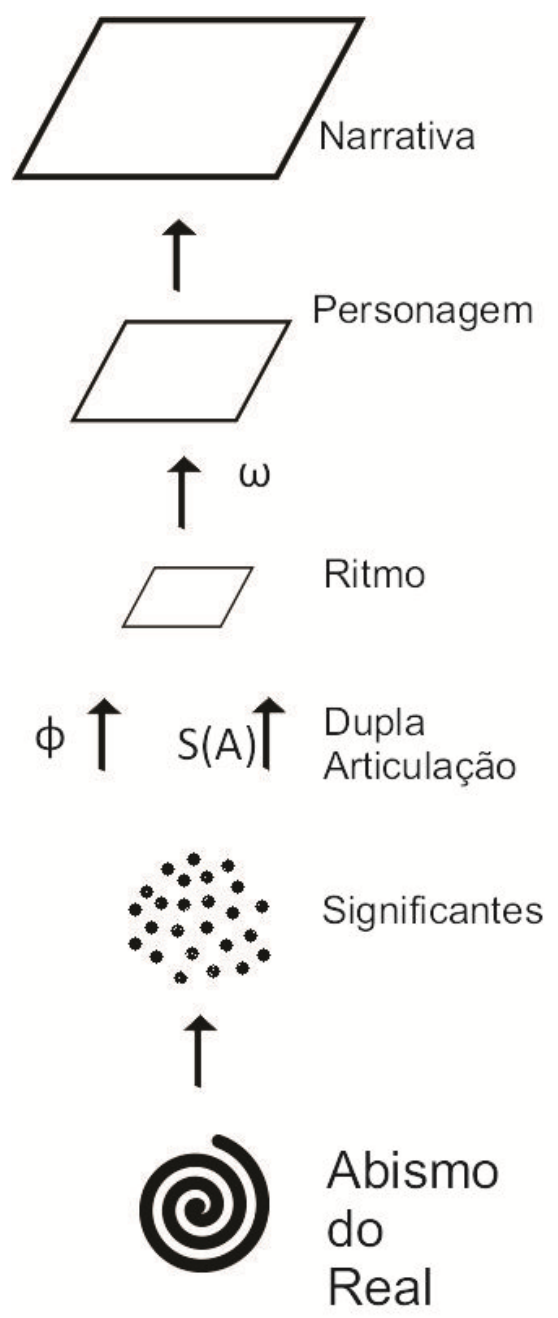

Figura 1 - Representação gráfica do procedimento de análise e o sentido do personagem como origem da narrativa no topo

\section{CONCLUSÃO}

Uma narrativa pode ser perversa se justifica o Real. Pode ser simplesmente fantasmática se o predica de outra forma. (SKARE, 2010b). Acreditamos que isso pode ser traçado ao sentido do personagem que origina essa narrativa.

Acreditamos também que a narrativa, por constituir um nível superior ao do personagem, deve possuir uma ordem interna própria. Um estudo propriamente narratológico deve deslindar como o sentido dos personagens influencia outros elementos como trama, enredo, ambientação e assim por diante.

No sentido da chamada "análise do discurso", alguns elementos presentes aqui podem ser úteis, na medida em que mesmo um personagem político nos meios de comunicação, por exemplo, possui um sentido e compõe uma narrativa.

Queremos chamar a atenção para um afeto específico que constitui um sentido do personagem muito particular: a angústia. 
Nosso desejo é o desejo do Outro, mas quando não sabemos o que somos para esse desejo, angustiamo-nos. O objeto que leva à angústia é o que Lacan chama de objeto pequeno a (ou objet petit a). "A angústia é uma experiência corporal, a experiência do objet a no momento de sua mutilação $e$ a experiência do desejo do Outro que se articula ao redor dessa mutilação.” (GONDEK, 2004, p. 233 - grifos no original).

Assim, quando o sentido do personagem é a angústia, diremos que isso pode dar origem a uma narrativa filosófica. É claro que outros afetos podem dar origem a uma narrativa dessas. Com diz Aristóteles, o espanto é o pai da filosofia - o mesmo espanto que o leitor encontra perante os versos diáfanos de Jules Laforgue.

\section{REFERÊNCIAS}

BEnjamin, W. Magia e Técnica, Arte e Política. São Paulo: Brasiliense, 1996.

Origem do Drama Trágico Alemão. Lisboa: Assírio \& Alvim, 2004.

BONVICINO, R. Características da Poesia. In: LAFORGUE, J. Litanias da Lua. São Paulo: Iluminuras, 1989. p. 19-27.

DOUZINAS, C. The End of Human Rights: critical legal thought at the turn of the century. Oxford: Hart Publishing, 2000.

FOWLIE, W. Poem \& Symbol: a brief history of French symbolism. Harrisburg: Penn State University Press, 1990.

GONDEK, H-D. From the Protective Shield against Stimuli to the Fantasm. In: STEWART, E; JAANUS, M; FELDSTEIN, R. Lacan in the German speaking world. New York: SUNY Press, 2004.

JAMES, R. C.; JAMES, G. Mathematics Dictionary. New York: Springer, 1992.

KOJÈVE, A. Introdução à Leitura de Hegel. Rio de Janeiro: Contraponto, 2010.

KRISTEVA, Julia. La révolution du langage poétique. Paris: Éditions du Seuil, 1974.

LACAN, J. O Estádio do Espelho como Formador da Função do Eu. In: ŽIŽEK, S. Um Mapa da Ideologia. Rio de Janeiro: Contraponto, 1996. p. 97-103.

Écrits: a selection. London: Routledge, 2001.

LAFORGUE, J. Poems of Jules Laforgue. London: Anvil Press, 2001.

LEFÈBVRE, H. Posição: contra os tecnocratas. São Paulo: Nova Crítica, 1969.

MYERS, T. Slavoj Žižek. London: Routledge, 2003.

PELT, T. V. The Other Side of Desire: Lacan's theory of the registers. New York: SUNY Press, 2000.

POE, E A. Sixty-seven Tales. New York: Gramercy Books, 1990.

SAUSSURE, F. Curso de Lingüística Geral. São Paulo: Editora Cultrix, 2003.

SKARE, N. G. Por uma Análise Rítmica. Linguagens: Revista de Letras, Artes e Comunicação (FURB), v. 3, p. 44-62, 2009.

. Informação, Memória e Narrativa em 'O Anel do General' de Selma Lagerlöf.

Revista Anagrama (USP), v. 1, p. 1-12, 2010a.

. Semiótica Lacaniana e Origem em Marthe de Huysmans: notas para uma tradução criativa. CASA (Araraquara), v. 8, p. 1-16, $2010 \mathrm{~b}$.

O Bosque que Cala e o Bosque que Canta: Projeto de Tradução de 'Walden' de Thoreau. Revista Anagrama (USP), v. 1, p. 1-13, 2011.

THOMPSON, W. J. Understanding Les Fleurs du Mal: Critical Readings. Nashville: Vanderbilt University Press, 1997. 
CASA, Vol.10 n.1, julho de 2012

ŽIŽEK, S. Looking Awry: an introduction to Jacques Lacan through popular culture. Cambridge: MIT Press, 1992.

Recebido em: 26/11/11

Aprovado em: 15/05/12 